\title{
Professional self-realization of disabled persons in an urban environment
}

\author{
Dmitry Sergeevich Raidugin ${ }^{{ }^{*}}$, Elmira Kamalovna Naberushkina ${ }^{1}$, Ekaterina Vladimirovna \\ Voevodina $^{1}$, Yevgeny Olegovich Kubyakin ${ }^{1}$, and Vladimir Valeryevich Plotnikov ${ }^{2}$ \\ ${ }^{1}$ Financial University under the Government of the Russian Federation, Department of Sociology, \\ Moscow, Russia \\ ${ }^{2}$ Krasnodar University of the Ministry of Internal Affairs of Russia, Department of Philosophy and \\ Sociology, Krasnodar, Russia
}

\begin{abstract}
The article is a review of the part of the research conducted in the framework of the grant of the Russian Foundation for Basic Research "Urban well-being of people with disabilities". The immediate subject of the article is professional self-realization as a factor of urban well-being of a person with a disability. Well-being is understood as a subjectively constructed phenomenon, that is, through the prism of people with disabilities' own perceptions of the sufficiency of conditions created in the urban environment for their professional self-realization and, as a consequence, for well-being in general. Professional self-realization has become one of the six factor groups that directly or indirectly influence the urban well-being of citizens with disabilities. Along with professional self-realization, the factors of urban well-being in the framework of the study were: trust in the government and involvement in management processes; the level of implementation of basic values; psychological comfort; accessibility of the spatial environment; and finally, the quality of social services. The five factor groups listed above are not discussed in the article, but the reader should have an idea of the context in which professional self-realization is studied. The study included two sub-samples, reflecting the specifics of a megalopolis (Moscow) and a regional center (Saratov).
\end{abstract}

Keywords: urban environment, disability, well-being of a person with a disability, urban well-being, professional self-realization

\section{$1 \quad$ Introduction}

Every person, at least once in his life, has asked himself the question of how much his everyday life corresponds to his own expectations. And hardly anyone has ever been able to answer this question in the affirmative, that is, to state that in each of the areas that are important to him, everyday life meets all his desires without exception, from "comfortable

\footnotetext{
* Corresponding author: $\underline{\text { raydmis@mail.ru }}$
} 
living conditions" to having people in his social environment who are exclusively "pleasant" to him.

If we imagine that everyday life includes a number of conditions that make it difficult, due to the presence of a disability, then in addition to typical problems, issues related to the environment are actualized.

There are many environmental factors on which the happiness of each of us depends. In this work, one of the most essential conditions for a person with a disability will be investigated: accessibility of urban space. Space should not be understood in a narrow sense, that is, as a set of buildings, structures, roads, and other material conditions, in which a person finds himself when he leaves the walls of his home. We interpret urban space with its manifold architectural, power and social ways of differentiation and distancing as a form reflecting social interactions in society. Spatial forms arise from social forms, urban architecture is shaped by social attitudes, and the city's physical barriers that "immobilize" disabled people reflect social interactions between disabled and non-disabled people [1]. In other words, together with the disability factor, the lack of adaptability of urban space not only contributes to the strengthening of physical barriers, but also stimulates the emergence of new circumstances that hinder the well-being of people with disabilities.

In this paper, well-being is thought of as a social reflection of happiness [2]. The basis for the restriction is the addition of such a property as the social conditionality of happiness, transferring the latter from the categorical plane to the conceptual plane and, as a consequence, from the disciplinary framework of philosophy to the sociological research field.

Confirmation of the validity of this approach can be found in many publications from universally recognized dictionaries to scientific articles. Thus, the Encyclopedic Dictionary of F.A. Brockhaus and I.A. Efron identifies the two concepts: "Well-being (Greek $\varepsilon v^{\prime} \delta \alpha \mu$ ovía) is the same as happiness, always subjectively understood by the attainment of all the goods (see this sl.) to which one aspires" [3]. This is also characteristic of a number of other encyclopedic sources. As far as scientific literature is concerned, the concept of well-being, as already noted, has found its reflection in many publications, the most methodologically referential of which we will take as a basis.

S.V. Yaremchuk defines well-being as "a person's satisfaction with the main spheres of life and life in general" [4]. Her study identifies indicators of well-being according to six main "modules" previously proposed by R.M. Shamionov [5]: 1) financial situation; 2) personal self-determination (assessment of the degree of self-realization); 3) social self-determination; 4) personal well-being (assessment of own character and individual characteristics); 5) professional self-determination and 6) physical and psychological health. Foreign colleagues Tom Rath and Jim Harter identify five main domains of well-being: 1) occupational well-being; 2) physical well-being; 3) social well-being; 4) financial well-being; and 5) environmental well-being [6], noting that to achieve happiness, success must be achieved in all five domains and failure in at least one domain cannot be compensated by well-being in the others. Another group of foreign authors led by I. Giovannini identifies six factors of well-being: 1) physical and mental health; 2) freedom and self-determination; 3) a good job; 4) satisfactory interpersonal relationships; 5) material well-being; 6) knowledge and understanding of the world [7].

Of the most pressing problems related to the one considered in this article, it is necessary to highlight: the impact of urban transformations on the well-being of citizens [8]; the relationship between income and subjective well-being [9]; the relationship between the quality of life and life crises [10]; social support and well-being in the student environment [11]; the impact of work on life satisfaction [12]; various aspects of well-being 
in the era of a pandemic [13-15]. It should be noted separately that we deliberately avoided studying the problem of the pandemic due to the fact that the data collection was carried out before the Covid-19 pandemic became a global phenomenon.

As we can see, most of the presented authors directly or indirectly include professional self-realization among the factors of well-being. This state of affairs allows us to formulate the thesis that the conditions of the urban environment, created for professional self-realization of citizens with disabilities, directly affect their well-being in general.

\section{$2 \quad$ Materials and methods}

As part of the implementation of the "Urban Well-Being of Persons with Disabilities" grant, a field survey was conducted in March-June 2019 to collect data on the well-being of people with disabilities in the urban environment. The quota sample of the questionnaire survey included two sub-samples in Moscow and Saratov. The total sample size was 497 people, which allows achieving a confidence interval of $4.4 \%$. Accordingly, the margin of error is $2.2 \%$.

The main quotas were distributed as follows:

- by gender (men $-48.5 \%$, women $-51.5 \%$ );

- by disability group (group $1-26.6 \%$; group $2-35.4 \%$; group $3-27.4 \%$; other categories $-10.7 \%$ ).

In addition to these grounds for quotas, the age composition, specifics of the underlying disease, and occupation were also taken into account. A more complete description of the research methodology is presented in the previously published article "Methodology and Methodology for Researching Opportunities for Professional Self-Actualization of People with Disabilities in the Context of the Problem of Urban Well-Being” [16].

To describe and analyze the data, mainly methods of descriptive statistics were used, which allowed to obtain the following statistically significant results:

- univariate frequency distributions for each of the studied indicators (will be described below in the relevant section of the article);

- description of modal groups;

- description of rank indicators;

- identification of an index of urban well-being for each indicator in two sub-samples: Moscow and Saratov;

- identification of the integral index of urban well-being of disability, as well as the integral index of well-being in the field of professional self-actualization, which allows comparing the results in general with the results of the factor group under study.

The purpose of this paper is to describe the level of satisfaction with professional self-realization opportunities of citizens with disabilities in the context of the problem of urban well-being.

\section{$3 \quad$ Results}

As stated earlier, the factor group "well-being in the sphere of professional fulfillment" was measured in our study through eight indicators, which include: standard of living; number of vacancies; level of offered salaries; opportunities for career development; availability of current professional connections; assessment of potential professional connections; diversity of employers; and finally, assessment of the level of trust in employers. 
Accordingly, the results were described for each of these eight indicators in two sub-samples - in Moscow and Saratov.

The well-being index was calculated according to the formula:

$$
\frac{0 \sum r 1+0.25 \sum r 2+0.5 \sum r 3+0.75 \sum r 4+1 \sum r 5}{R}
$$

where $r 1$ - respondents who chose a score of " 1 " (metric value " 0 ");

$r 2$ - respondents who chose the mark " 2 " (metric value " 0.25 ")

$r 3$ - respondents who chose a score of " 3 " (metric value " 0.5 ")

$r 4$ - respondents who chose a score of " 4 " (metric value " 0.75 ”)

$r 5$ - respondents who chose the rating " 5 " (metric value " 1 ");

$R$ - total number of respondents who chose one of the non-zero values.

Accordingly, the index is distributed over five values: 0-0.2 - low well-being; 0.21-0.4 - below average; 0.41-0.6 - average; 0.61-0.8 - above average; 0.81-1 - high well-being.

Below we will consider each of the indicators separately.

Indicator 1. Standard of living

The overall level of well-being according to the indicator "standard of living" is average (0.58).

The difference between the Moscow (0.7 - above average) and Saratov (0.4 - below average) sub-samples is 0.3 .

Modal groups:

- Total (34.8\%) - in the value of "4";

- in the Moscow subsample (50\%) - in the value of " 4 ";

- in the Saratov subsample (30.8\%) in the value of " 1 ".

Ranking scores:

- Overall, 21.6\% of respondents are dissatisfied with their standard of living, $26.2 \%$ are satisfied, and $51.1 \%$ are satisfied;

- in Moscow $6.6 \%$ of the respondents are dissatisfied with the standard of living, $24.2 \%$ - satisfied, and $68.9 \%$ - satisfied;

- in Saratov, $44.6 \%$ of those polled were dissatisfied with their standard of living, $29.2 \%$ were satisfied, and $23.6 \%$ were satisfied.

Indicator 2. Number of vacancies

The overall level of well-being according to the indicator "number of vacancies" is average (0.44).

The difference between the Moscow (0.49 - average) and Saratov (0.35 - below average) subsamples is 0.14 .

Modal groups:

- general $(22.7 \%)$ - in the value of " 2 ";

- in the Moscow subsample (27.8\%) - in the value of "3";

- in the Saratov subsample (28.7.8\%) in the value "1".

Ranking scores:

- overall $44.7 \%$ of respondents are dissatisfied with the number of vacancies, $22.1 \%$ are satisfied, and $33.2 \%$ are satisfied;

- in Moscow 37.5\% of respondents are dissatisfied with the number of vacancies, $27.8 \%$ - satisfied, $34.7 \%$ - satisfied;

- In Saratov, 65.9 percent of the respondents are dissatisfied with the number of vacancies, 13.3 percent are satisfied, and 20.8 percent are satisfied.

Indicator 3. Wage level 
The overall level of well-being according to the indicator "level of salaries" is below average (0.38).

The difference between the Moscow (0.49 - average) and Saratov (0.21 - below average) subsamples is 0.28 .

Modal groups:

- General (29.8\%) - in the value of "1";

- in the Moscow subsample (31.8\%) - in the value of "3";

- in the Saratov subsample (48.7\%) in the value " 1 ".

Ranking scores:

- overall $48.2 \%$ of respondents are dissatisfied with wages, $26.2 \%$ are satisfied, and $25.6 \%$ are satisfied;

- in Moscow 34\% of respondents are dissatisfied with the level of salaries, $31.8 \%-$ satisfied, $34.2 \%$ - satisfied;

- in Saratov $69.7 \%$ of the respondents are dissatisfied with the level of wages, $17.4 \%$ satisfied, $8.2 \%$ - satisfied. Characteristically, "5" was not chosen by any of the Saratov respondents.

Indicator 4. Opportunities for career development

The overall level of well-being according to the indicator "career development opportunities" is average $(0.47)$.

The difference between the Moscow (0.58 - average) and Saratov (0.29 - below average) subsamples is 0.29 .

Modal groups:

- Total $(23.7 \%)$ - in the value of " $3 " ;$

- in the Moscow subsample (27.8\%) - in the value of "4";

- in the Saratov subsample (33.3\%) in the value of " 1 ".

Ranking scores:

- overall, 39.6\% of respondents are dissatisfied with career development opportunities, $23.7 \%$ are satisfied, and $36.7 \%$ are satisfied;

- In Moscow, 24.6\% of respondents are dissatisfied with career development opportunities, $25.8 \%$ - satisfied, and $49.6 \%$ - satisfied;

- In Saratov, $62.6 \%$ of the respondents are dissatisfied with the career development opportunities, $20.5 \%$ - satisfied, and $16.9 \%$ - satisfied.

Indicator 5. Current Professional Connections

The overall level of well-being according to the indicator "current professional connections" is average $(0.45)$.

The difference between the Moscow (0.47 - average) and Saratov (0.42 - average) subsamples is 0.05 .

Modal groups:

- Total (29.4\%) - in the value of "3";

- in the Moscow subsample (34.1\%) - in the value of " 3 ";

- in the Saratov subsample $(27.7 \%)$ in the value " 1 ".

Ranking scores:

- overall $37.4 \%$ of respondents are dissatisfied with the number of actual professional connections, $29.4 \%$ are satisfied, and $33.2 \%$ are satisfied;

- in Moscow 34.6\% of respondents are dissatisfied with the number of current professional relations, $34.1 \%$ - satisfied, and $31.3 \%$ - satisfied;

- In Saratov, $41.5 \%$ of the respondents are dissatisfied with the number of current professional contacts, $22.1 \%$ are satisfied, and $36.4 \%$ are satisfied.

Indicator 6. Potential professional connections 
The overall level of well-being according to the indicator "potential to acquire professional connections" is average (0.44).

The difference between the Moscow (0.49 - average) and Saratov ( 0.35 - below average) sub-samples is 0.14 .

Modal groups:

- Total (29.8\%) - in the value of " 3 ";

- in the Moscow subsample (34.1\%) - in the value of "3";

- in the Saratov subsample (35.4\%) in the value "1".

Ranking scores:

- overall, $38.7 \%$ of respondents are dissatisfied with professional networking opportunities, $29.8 \%$ are satisfied, and $31.5 \%$ are satisfied;

- In Moscow, $30.7 \%$ of those polled were dissatisfied with the opportunity to acquire professional connections, $34.1 \%$ were satisfied, and $35.2 \%$ were satisfied;

- In Saratov $50.8 \%$ of those polled were dissatisfied with the opportunity to acquire professional connections, $23.1 \%$ were satisfied, and $26.1 \%$ were satisfied.

Indicator 7. Diversity of the circle of employers

The overall level of well-being according to the indicator "diversity of the circle of employers" is average (0.45).

The difference between the Moscow ( 0.5 - average) and Saratov ( 0.39 - below average) subsamples is 0.11 .

Modal groups:

- Total $(25.6 \%)$ - in the value of " 3 ";

- in the Moscow subsample (31.1\%) - in the value of " 3 ";

- in the Saratov subsample (28.2\%) in the value "2".

Ranking scores:

- overall $41.4 \%$ of respondents are dissatisfied with the diversity of employers, $25.6 \%$ are satisfied, and $33.3 \%$ are satisfied;

- in Moscow 32.8\% of the respondents are dissatisfied with the diversity of the circle of employers, $31.1 \%$ - satisfied, and $36.1 \%$ - satisfied;

- in Saratov $54.4 \%$ of the respondents are not satisfied with the diversity of employers, $16.9 \%$ are satisfied, and $28.7 \%$ are satisfied.

Indicator 8. Confidence in employers

The overall level of well-being according to the indicator "confidence in employers" is average (0.51).

The difference between the Moscow (0.52 - average) and Saratov (0.49 - average) subsamples is 0.02 .

Modal groups:

- Total $(27.6 \%)$ - in the value of " 3 ";

- in the Moscow subsample (35.1\%) - in the value of "3";

- in the Saratov sub-sample (20.5\%) Modal groups were distributed in two polar values at once: "1" and " 5 ".

Ranking scores:

- overall, $31.1 \%$ of respondents do not trust employers, $27.6 \%$ show an average level of trust, and $41.3 \%$ are above average or high;

- In Moscow, $25.5 \%$ of those polled did not trust their employers, $35.1 \%$ showed an average level of trust, and $39.4 \%$ an above average or high level of trust;

- in Saratov $39.5 \%$ of the interrogated do not trust their employers, $15.9 \%$ have an average level of trust, and $44.6 \%$ have an above average or high level of trust.

Conclusion on the group of indicators "opportunities for professional self-realization" 


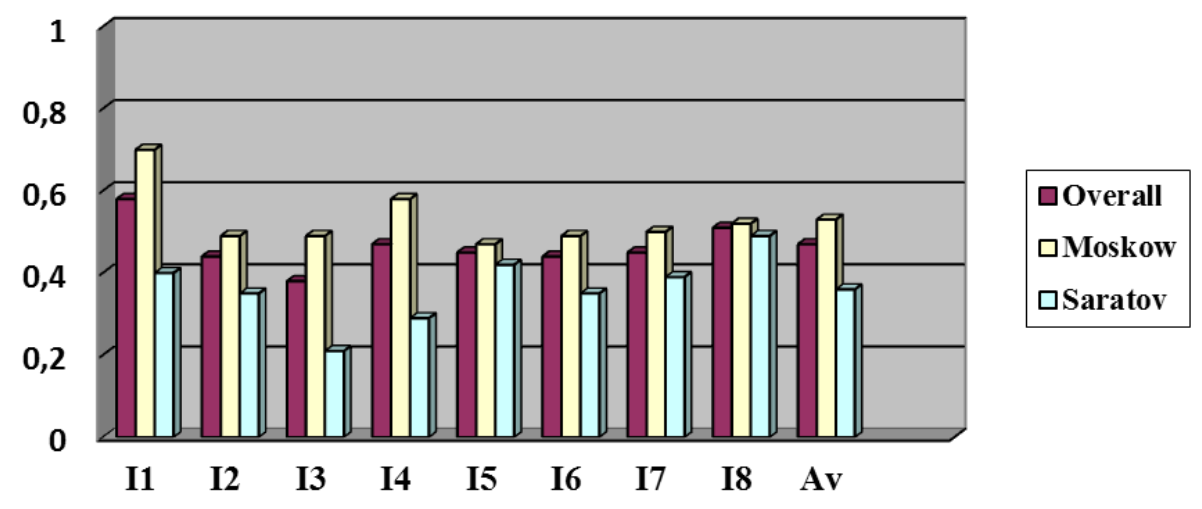

Fig. 1: Comparison of indicators of well-being in the sphere of professional self-actualization. Source: compiled by the authors.

\section{Discussion}

The overall well-being index for the group of indicators "opportunities for professional self-actualization" is 0.47 . The difference between the Moscow (0.53) and Saratov (0.36) sub-samples is 0.17 . In our opinion, this difference is very significant and reflects the real difference in the possibilities of professional self-realization in the capital and the regional center, which is Saratov. If the trend recorded in Saratov is confirmed in other regional centers, then it is fair to assume that with a more expanded study with all-Russian geography and the corresponding sample, reflecting the real distribution of population between the capital and regional centers, the index of well-being in the sphere of professional self-realization will be lower than the obtained (0.47), approaching the negative zone of 0.4 or lower.

Overall sample. There are no indices in the "positive" zone (0.61 and above). In the "negative" zone (0.4 and below) is the index of satisfaction with the level of wages $(0.38)$. The most favorable situation -0.58 - is observed in assessing the standard of living, the least favorable -0.38 - in assessing the level of wages. The difference between the highest and lowest indices is 0.2 . This result suggests the presence of environmental barriers that accompany the professional self-realization of citizens with disabilities.

Moscow sub-sample. In the "positive" zone there is an index of satisfaction with the standard of living (0.7). There are no indices in the "negative" zone. The most prosperous situation $-0.7-$ is observed in the assessment of the standard of living, the least prosperous -0.47 - in the assessment of actual professional connections. The difference between the highest and lowest indices is 0.23 . Despite the presence of one of the indices in the positive zone, we are forced to make the disturbing conclusion that even in the capital the index of well-being in the sphere of professional self-realization is mostly in the average values. However, even if we talk about the value of 0.7 in the assessment of living standards in Moscow, it does not add optimism for city residents with disabilities: this variable does not reflect the respondent's assessment of living standards, but only reflects his opinion about living standards of city residents in general. In other words, the question about the standard of living in the city referred the respondent not to the assessment of their own standard of living, but to the assessment of the standard of living of others. 
Saratov sub-sample. There are no indices in the "positive" zone. In a negative zone there are indices of satisfaction with living standards (0.4), number of vacancies $(0.35)$, salary level $(0.21)$, possibilities for career development $(0.29)$, potential professional connections (0.39) and variety of employers (0.35). The most favorable situation $-0.49-$ is observed in assessing confidence in employers, the least favorable -0.21 - in assessing the level of wages. The difference between the highest and lowest indices is 0.28 . As can be seen from these summary statistics, six out of eight indices of the factor group "professional self-actualization" are in the negative zone. As previously stated, the significant difference between the integral indices in the two subsamples reflects the real difference between the level of well-being in Moscow and the regional center. Moreover, one cannot ignore the fact that the assessment of wages in Saratov is close to critical (0.21). The desire of regional residents to move to the capital is understandable. However, as we noted above, even in the capital they can expect only an average level of well-being in the sphere of professional fulfillment.

\section{Conclusion}

As the results of the questionnaire survey showed, the level of well-being of citizens with disabilities in the field of professional self-realization is located in the average values (0.47), which fully correlate with the overall index of well-being in all six indicator groups, which according to the results of the study was 0.52 . Professional self-actualization, being an inherent attribute of urban well-being in general, has a direct impact on the satisfaction of city residents with disabilities with their lives.

As a practical conclusion of this study, it should be suggested to the authorities and employers to pay attention to the problem areas, which include the level of wages, accessibility of jobs, career opportunities, and some others.

In the future, a similar study should be conducted on an all-Russian sample and regular measurements should be taken to assess the effectiveness of federal and regional programs aimed at improving the well-being of people with disabilities, as well as the dynamics of change in the situation.

\section{References}

1. E.K. Naberushkina, Disabled People in the Big City: Problems of Social Citizenship (Variant, Moscow, 2012)

2. D.S. Raidugin, E.V. Voevodina, Man. Soc. Incl, 34, 23-28 (2018)

3. Entsiklopedicheskii slovar F.A. Brokgauza i I.A. Efrona. Blagopoluchie [Encyclopedic dictionary of F. A. Brockhaus and I. A. Efron. Wellbeing]. Accessed on: September 26, 2021. [Online]. Available: https://dic.academic.ru/dic.nsf/brokgauz_efron/13583/

4. S.V. Yaremchuk, Psych J, 34, 89 (2013)

5. R.M. Shamionov, Psychology of the subjective well-being of personality (Publishing house of Saratov University, Saratov, 2004)

6. T. Rath, J. Harter, Wellbeing: The Five Essential Elements (Gallup Press, New York, 2010)

7. L.I. Galiakhmetova, Bul Bashkir Univ, 20, 1115 (2015)

8. Y.-C. Chiang, et al., J Urban Plan Devel, 147(4) (2021).

https://doi.org/10.1061/(ASCE)UP.1943-5444.0000740 
9. T. Muhammad, S. Srivastava, T.V. Sekher, BMC Psych, 9, 82 (2021). https://doi.org/10.1186/s40359-021-00588-5

10. X. Li, H. Chen, Z. Zhu, BMC Pub Health, 21, 774 (2021). https://doi.org/10.1186/s12889-021-10861-2

11. M. Yildirim, F.Ç. Tanrıverdi, J Pos Sch Psy, 5(2), 127-135 (2021). https://doi.org/10.47602/JPSP.V5I2.229

12. M.D. Merino, J. Privado, R. Durán, Anales de Psica, 37(3) (2021). https://doi.org/10.6018/analesps.430801

13. R. Clair, M. Gordon, M. Kroon, C. Reilly, Human Soc Sci Comm, 8, 28 (2021). https://doi.org/10.1057/s41599-021-00710-3

14. M. Juchnowicz, H. Kinowska, Information, 12(8), 293 (2021). https://doi.org/10.3390/info12080293

15. V. Van Acker, L. Ho, C. Mulley, Transp Res Part A: Pol Prac, 151, 214-227 (2021). https://doi.org/10.1016/j.tra.2021.07.010

16. D.S. Raidugin, E.K. Naberushkina, S.P. Gorbunov, Human, Soc-Econ Soc Sci, 12, 110-116 (2019) 